NISTIR 8065

\title{
Measurement of Dynamic Impact Toughness on Impact-Tested Precracked Charpy Specimens
}

Enrico Lucon

This publication is available free of charge from:

http://dx.doi.org/10.6028/NIST.IR.8065

National Institute of Standards and Technology U.S. Department of Commerce 
NISTIR 8065

\title{
Measurement of Dynamic Impact Toughness on Impact-Tested Precracked Charpy Specimens
}

\author{
Enrico Lucon \\ Applied Chemicals and Materials Division \\ Material Measurement Laboratory
}

This publication is available free of charge from:

http://dx.doi.org/10.6028/NIST.IR.8065

July 2015

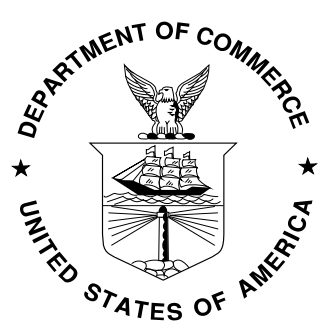

U.S. Department of Commerce Penny Pritzker, Secretary

National Institute of Standards and Technology Willie May, Under Secretary of Commerce for Standards and Technology and Director 
Certain commercial entities, equipment, or materials may be identified in this document in order to describe an experimental procedure or concept adequately. Such identification is not intended to imply recommendation or endorsement by the National Institute of Standards and Technology, nor is it intended to imply that the entities, materials, or equipment are necessarily the best available for the purpose.

National Institute of Standards and Technology Internal Report 8065

Natl. Inst. Stand. Technol. Int. Report 8065, 14 pages (July 2015) CODEN: NTNOEF

This publication is available free of charge from:

http://dx.doi.org/10.6028/NIST.IR.8065 


\begin{abstract}
The Fraunhofer Institute for Mechanics of Materials (IWM, Freiburg, Germany) and the Materials Testing Institute University of Stuttgart (MPA Stuttgart, Germany) have recently launched a joint collaboration project titled "Dynamic Mastercurves II” (MC-Dyn II). The project focuses on the measurement of the ductile-to-brittle transition toughness at impact loading rates, in part by means of fatigue precracked and side-grooved Charpy-type specimens (PCC specimens). IWM and MPA invited NIST Boulder to contribute to the project by testing PCC specimens of a reactor pressure vessel (RPV) steel and determining the dynamic Master Curve reference temperature, $T_{0, \mathrm{~d}}$, in accordance with ASTM E1921-14a. Tests at NIST were performed on an instrumented impact machine at $0{ }^{\circ} \mathrm{C}$ and with an impact velocity $v_{0} \approx 1.21 \mathrm{~m} / \mathrm{s}$. The calculated reference temperature $T_{0, \mathrm{~d}}=-7.5{ }^{\circ} \mathrm{C}$, corresponding to an average loading rate of $3.3 \times 10^{5}$ $\mathrm{MPa} \sqrt{\mathrm{m}} / \mathrm{s}$, is in excellent agreement with the results previously published by IWM under similar conditions $\left(T_{0, \mathrm{~d}}=-7^{\circ} \mathrm{C}\right)$. To the author's knowledge, these are the first tests of this type ever performed at NIST Boulder.
\end{abstract}

\title{
Keywords
}

Dynamic fracture toughness; dynamic reference temperature; impact loading rates; instrumented Charpy tests; Master Curve; precracked Charpy-type (PCC) specimens; reactor pressure vessel steel. 


\section{Table of Contents}

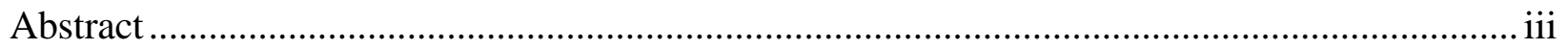

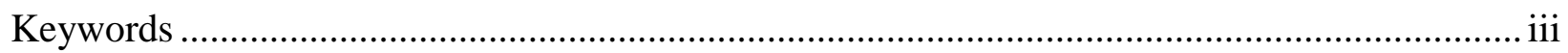

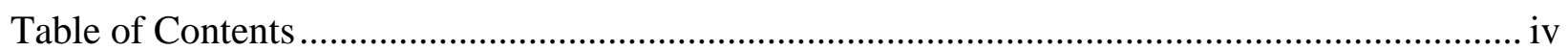

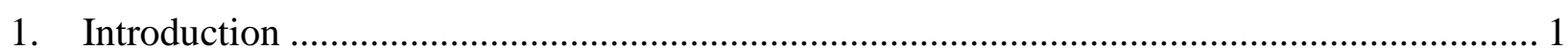

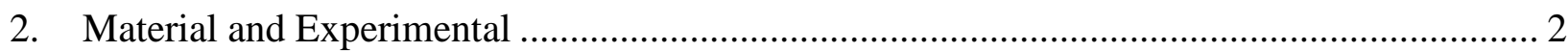

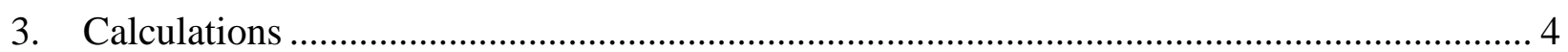

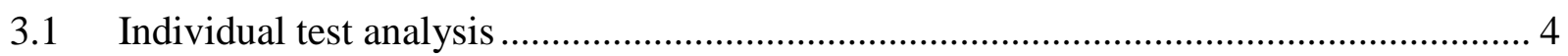

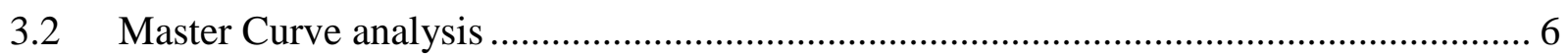

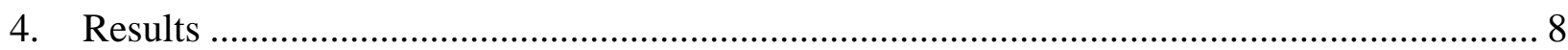

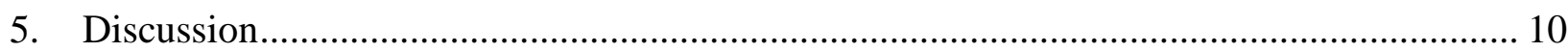

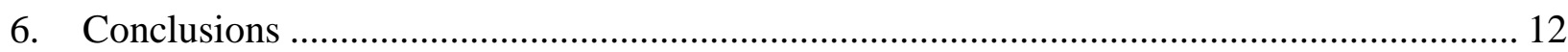

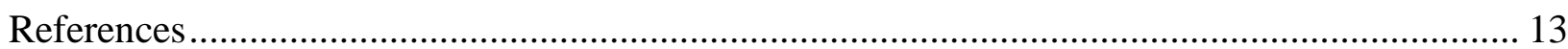




\section{Introduction}

The ASTM E1921 standard, titled "Standard Test Method for Determination of Reference Temperature, $T_{0}$, for Ferritic Steels in the Transition Range," covers the characterization of the fracture toughness of ferritic steels that experience the onset of cleavage (unstable) crack propagation under elastic or elastic-plastic conditions. Its first edition was published in 1997, and the current version is E1921-14a [1].

The E1921 standard allows the determination of the so-called reference temperature $T_{0}$, which represents the temperature at which compact tension, $\mathrm{C}(\mathrm{T})$, specimens of $1 \mathrm{in} .(25.4 \mathrm{~mm})$ thickness, 1TCT, have a median fracture toughness $K_{\mathrm{Jc}}=100 \mathrm{MPa} \sqrt{\mathrm{m}}$ [2]. The parameter $T_{0}$ is all that is needed to characterize fracture toughness in the ductile-to-brittle transition region, since the shape of the Master Curve is universal for all ferritic steels [3]. The effect of specimen size on fracture toughness is treated by the use of the weakest-link theory [4] applied to a three-parameter Weibull distribution of fracture toughness values. Statistical methods are employed to predict the specific transition toughness curve and specific tolerance bounds for the material tested.

The reference temperature $T_{0}$ is dependent on loading rate, and has been shown to increase with increasing loading rate [5]. For reactor pressure vessel (RPV) steels used in the nuclear industry, the so-called ASTM reference curve $K_{\mathrm{IR}}$ is used as a lower-bound curve which limits the embrittlement that can be observed and measured [6]. In the nuclear field, elevated loading rates are often used as a surrogate of neutron irradiation for studying embrittlement phenomena of RPV steels.

In 2012, the Fraunhofer Institute for Mechanics of Materials (IWM, Freiburg, Germany) and the Materials Testing Institute University of Stuttgart (MPA Stuttgart, Germany) have collaborated in a joint project aimed at verifying the lower-bound $K_{\text {IR }}$ curve for a German RPV steel denominated 22NiMoCr37 (ASTM A508 cl. 2) at elevated loading rates [7]. The results of the project confirmed the conservatism of the ASME $K_{\mathrm{IR}}$ curve in comparison to the dynamic fracture toughness values measured on specimens of different configuration (compact tension, single-edge bend) and size at loading rates in the range $\mathrm{d} K / \mathrm{d} t=10^{5} \mathrm{MPa} \sqrt{\mathrm{m}} / \mathrm{s}-10^{7} \mathrm{MPa} \sqrt{\mathrm{m}} / \mathrm{s}$.

In 2014, IWM and MPA invited NIST to contribute to a follow-up collaborative joint project titled "Dynamic Mastercurves II" (MC-Dyn II), in which Wolfgang Böhme is Project Coordinator and Project Leader at IWM and Uwe Mayer is Project Leader at MPA. NIST was asked to test 25 precracked and side-grooved Charpy-type specimens of $22 \mathrm{NiMoCr} 37$ at $0{ }^{\circ} \mathrm{C}$ and loading rates on the order of $10^{5} \mathrm{MPa} \sqrt{\mathrm{m}} / \mathrm{s}$. The specimens had to be tested on an instrumented impact pendulum with a reduced impact speed $\left(v_{0} \approx 1.2 \mathrm{~m} / \mathrm{s}\right)$ and the dynamic reference temperature $T_{0 \text {,dyn }}$ had to be established in accordance with ASTM E1921-14a.

To the author's knowledge, this is the first time dynamic toughness tests on precracked Charpy-type (PCC) specimens have been performed at NIST Boulder. 


\section{Material and Experimental}

The material tested is a German RPV steel denominated 22NiMoCr37, which corresponds to ASTM A508 cl. 2. Its measured chemical composition is given in Table 1, and Table 2 provides basic mechanical properties as reported in $[7,8]$.

Table 1 - Chemical composition of 22NiMoCr37 steel, wt \%.

\begin{tabular}{|cccccc|cccccc|}
\hline $\mathbf{C}$ & $\mathbf{S i}$ & $\mathbf{M n}$ & $\mathbf{P}$ & $\mathbf{S}$ & $\mathbf{M o}$ & $\mathbf{N i}$ & $\mathbf{C r}$ & $\mathbf{C u}$ & $\mathbf{V}$ & $\mathbf{C o}$ & $\mathbf{A l}$ \\
\hline 0.18 & 0.15 & 0.82 & 0.005 & 0.008 & 0.54 & 0.96 & 0.39 & 0.08 & $<0.01$ & 0.014 & 0.016 \\
\hline
\end{tabular}

Table 2 - Basic mechanical properties of 22NiMoCr37 [7,8].

\begin{tabular}{|c|l|}
\hline Tensile properties at $20^{\circ} \mathrm{C}$ & $\begin{array}{l}\text { Yield strength, } R_{\mathrm{el}}=430 \mathrm{MPa} \\
\text { Tensile strength, } R_{\mathrm{m}}=587 \mathrm{MPa}\end{array}$ \\
\hline Charpy properties $T_{\mathrm{XJ}}$ & $T_{28 \mathrm{~J}}=-40^{\circ} \mathrm{C}$ \\
(temperatures corresponding & $T_{41 \mathrm{~J}}=-31^{\circ} \mathrm{C}$ \\
to X J absorbed energy) & $T_{68 \mathrm{~J}}=-17^{\circ} \mathrm{C}$ \\
\hline Nil Ductility Reference Temperature $^{1}$ & $R T_{\mathrm{NDT}}=-20^{\circ} \mathrm{C}$ \\
\hline Quasi-static Reference Temperature $^{2}$ & $T_{0}=-68^{\circ} \mathrm{C}$ \\
\hline
\end{tabular}

The Charpy-type specimens for this project were extracted from the beltline of the reactor pressure vessel of Biblis C, which was never in operation. The specimens were machined in T-S orientation, with the crack propagating through the thickness from the inner diameter and the fatigue precrack tip located in the region between $2 / 3$ and $3 / 4$ of the vessel thickness.

In order to facilitate the initiation of the fatigue precrack, a narrow $\mathrm{EDM}^{3}$ slot was machined instead of a conventional Charpy notch ( $45^{\circ}$ notch angle with $2 \mathrm{~mm}$ notch depth). Twenty-five specimens were fatigue precracked at IWM Freiburg, than side-grooved to $80 \%$ of the original thickness at MPA Stuttgart, and finally shipped to NIST ${ }^{4}$. Table 3 reports the average values and standard deviations for the specimen dimensions (width $W$, thickness $B$, net thickness $B_{\mathrm{N}}$, and initial crack size $a_{0}$ ), all measured after the specimens had been tested. The average value of the ratio between initial crack size and specimen width is $a_{0} / W=0.330 \pm 0.007$.

Table 3 - Average values and standard deviations of specimen dimensions.

\begin{tabular}{|ccccc|}
\cline { 2 - 5 } \multicolumn{1}{c|}{} & $\begin{array}{c}\boldsymbol{W} \\
(\mathbf{m m})\end{array}$ & $\begin{array}{c}\boldsymbol{B} \\
(\mathbf{m m})\end{array}$ & $\begin{array}{c}\boldsymbol{B}_{\mathbf{N}} \\
(\mathbf{m m})\end{array}$ & $\begin{array}{c}\mathbf{a}_{\mathbf{0}} \\
(\mathbf{m m})\end{array}$ \\
\hline Average & 10.00 & 9.99 & 8.07 & 3.30 \\
\hline Stand. dev. & 0.037 & 0.025 & 0.055 & 0.077 \\
\hline
\end{tabular}

Tests were conducted on an instrumented pendulum machine with $406.5 \mathrm{~J}$ energy capacity and $134^{\circ}$ fall angle at full swing, corresponding to a maximum impact speed of $5.47 \mathrm{~m} / \mathrm{s}$. The

\footnotetext{
${ }^{1}$ Maximum temperature where a standard drop-weight specimen breaks when tested according to the provisions of ASTM E208-06(2012). This temperature is used for the establishment of the ASME $K_{\mathrm{IR}}$ lower bound curve.

${ }^{2}$ Corresponding to a quasi-static loading rate on the order of $1 \mathrm{MPa} \sqrt{\mathrm{m}} / \mathrm{s}$.

${ }^{3}$ Electro-Discharge Machining.

${ }^{4}$ At the time of testing, NIST was not equipped for fatigue precracking of Charpy-type specimens.
} 
instrumented striker conforms to the geometry of the ASTM E23-12b standard, having a striking edge radius of $8 \mathrm{~mm}$. Impact tests on PCC specimens were performed at reduced speed, which was obtained by dropping the pendulum from a lower angle $\alpha \approx 23.6^{\circ}$, resulting in an approximate impact speed of $1.21 \mathrm{~m} / \mathrm{s}$ and a potential energy of $20 \mathrm{~J}$. Average values for the test parameters are given in Table 4 along with standard deviations.

Table 4 - Average values and standard deviations of test parameters (fall angle, potential energy and impact speed).

\begin{tabular}{|cccc|}
\cline { 2 - 4 } \multicolumn{1}{c|}{} & $\begin{array}{c}\boldsymbol{\alpha} \\
\left.\mathbf{(}^{\circ}\right)\end{array}$ & $\begin{array}{c}\boldsymbol{E}_{\boldsymbol{p}} \\
(\mathbf{J})\end{array}$ & $\begin{array}{c}\boldsymbol{v}_{\mathbf{0}} \\
(\mathbf{m} / \mathbf{s})\end{array}$ \\
\hline Average & 23.58 & 20.01 & 1.2137 \\
\hline Stand. dev. & 0.025 & 0.042 & 0.001 \\
\hline
\end{tabular}

Data from the instrumented striker, amplified with a gain factor of approximately 200, were acquired at a sampling rate of $2 \mathrm{MHz}$, and transferred to a personal computer via an analog-todigital converter unit. The electric output $(\mathrm{mV})$ from the strain gages applied to the striker was converted into force $(\mathrm{kN})$ by means of the static calibration of the instrumented striker (Figure 1). No further correction or adjustment was applied to the instrumented data.

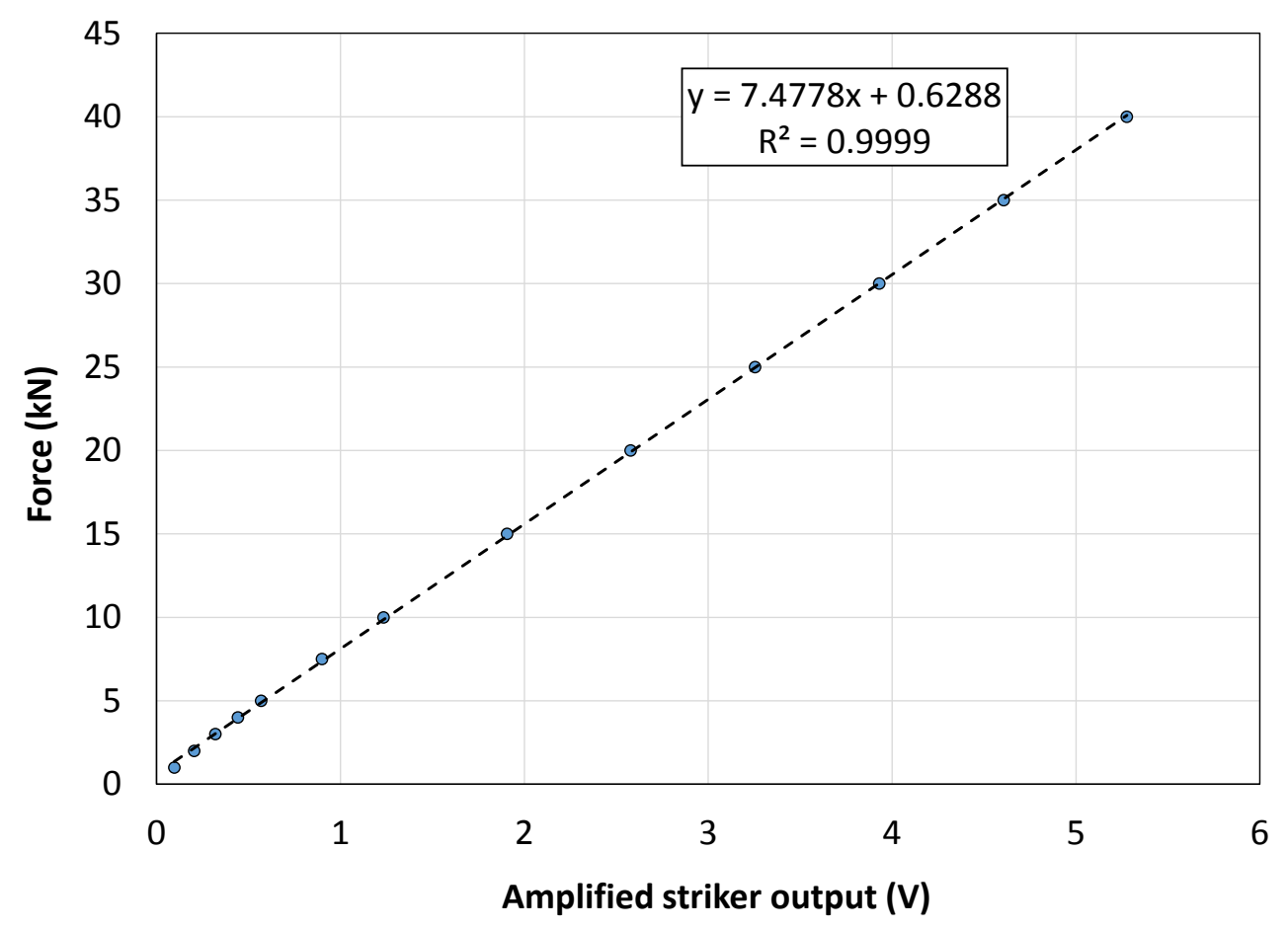

Figure 1 - Static calibration of the instrumented striker used for the tests. 


\section{Calculations}

\subsection{Individual test analysis}

The raw data file of each test, containing time and force data, was first processed to obtain velocity $v(t)$, displacement $s(t)$, and absorbed energy $W(t)$ in accordance with ASTM E2298-13 [9]:

$$
\begin{aligned}
& v(t)=v_{0}-\frac{1}{m_{t_{0}}} \int_{t_{0}}^{t} F(t) d t \\
& s(t)=\int_{t_{0}}^{t} v(t) d t \\
& W(s)=\int_{s_{0}}^{s} F(s) d s
\end{aligned}
$$

where $t_{0}, v_{0}$, and $s_{0}$ are time, velocity, and displacement corresponding to the start of the test.

The points corresponding to general yield ( $g y)$ and unstable fracture ( $b f$ ) were then visually identified on the force/displacement test record, as well as the initial linear elastic portion of the curve, which was fitted by a straight line (excluding the first inertia peak - see Figure 2).

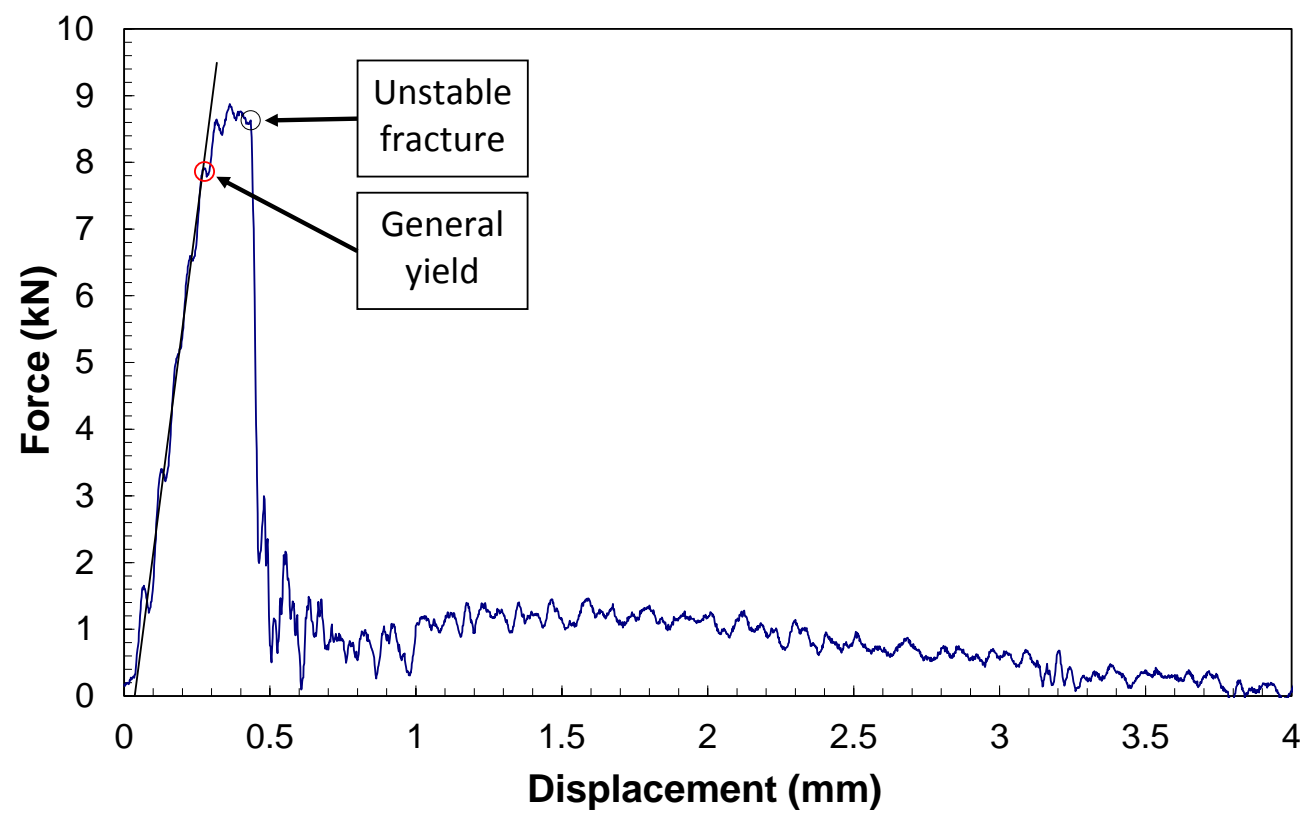

Figure 2 - Force/displacement test record for specimen 4A.

The following validity conditions have to be fulfilled for the test to be valid [10]:

(a) The potential energy $\left(E_{\mathrm{p}}\right)$ must be greater than three times the absorbed energy at maximum force $\left(W_{\mathrm{m}}\right)$, to avoid an excessive decrease of hammer speed during the test:

$$
E_{p}>3 W_{m} .
$$


(b) The time corresponding to unstable fracture $\left(t_{\mathrm{f}}\right)$ must be greater than three times the period of oscillation $(\tau)$ of the specimen/striker system, to ensure that inertial oscillations have sufficiently dampened and do not prevent a reliable identification of the initiation of unstable fracture:

$$
t_{f}>3 \tau .
$$

Both requirements, eqs. 4 and 5, were satisfied by all the tests performed.

In accordance with ASTM E1921-14a, the stress intensity factor at unstable fracture, $K_{\mathrm{Jc}}$, is calculated from the corresponding value of $J$-integral, $J_{\mathrm{C}}$, using:

$$
K_{J c}=\sqrt{\frac{J_{c} E}{1-v^{2}}}
$$

where $E=212 \mathrm{GPa}$ is the Young's modulus at the test temperature $\left(0{ }^{\circ} \mathrm{C}\right)$, and $v$ is Poisson's ratio (0.3).

The value $J_{\mathrm{c}}$ is calculated as the sum of an elastic $\left(J_{\mathrm{el}}\right)$ and a plastic $\left(J_{\mathrm{pl}}\right)$ component, respectively, given by:

$$
J_{e l}=\frac{K_{c}^{2}\left(1-v^{2}\right)}{E}
$$

with:

$$
K_{c}=\frac{F_{b f} S}{\sqrt{B B_{N}} W^{1.5}} f\left(\frac{a_{0}}{W}\right)
$$

( $F_{\text {bf }}=$ force at unstable fracture; $S=42 \mathrm{~mm}$, span or distance between the machine supports; the elastic function $f\left(a_{0} / W\right)$ is given in E1921-14a), and:

$$
J_{p l}=\frac{1.9 \cdot W_{b f, p l}}{B_{N}\left(W-a_{0}\right)}
$$

where the plastic part of the absorbed energy at unstable fracture is:

$$
W_{b f, p l}=W_{b f}-\frac{C_{0} F_{b f}^{2}}{2}
$$

with $W_{\mathrm{bf}}=$ absorbed energy at unstable fracture and $C_{0}=$ reciprocal of the initial elastic slope in $\mathrm{mm} / \mathrm{kN}$ (Figure 2).

The value $K_{\mathrm{Jc}}$ calculated via eqs. 6-10 needs to be finally validated by comparison with the maximum specimen capacity, expressed as:

$$
K_{J c(\text { limit })}=\sqrt{\frac{E\left(W-a_{0}\right) \sigma_{Y S}}{30\left(1-v^{2}\right)}}
$$

where $\sigma_{\mathrm{YS}}$ is the material's yield strength at the test temperature and relevant loading rate. For our analyses, a dynamic yield strength value $\sigma_{\mathrm{YS}}=558 \mathrm{MPa}$ was used, based on dynamic tensile tests performed at MPA Stuttgart. 


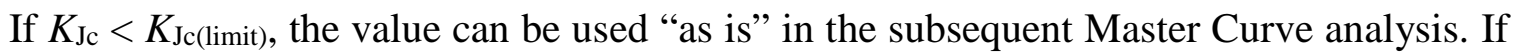
$K_{\mathrm{Jc}} \geq K_{\mathrm{Jc}(\mathrm{limit})}$, the value is censored and replaced with $K_{\mathrm{Jc}(\mathrm{limit})}$ in the Master Curve analysis. As will be seen in the following, only two of the 24 tests performed yielded a $K_{\mathrm{Jc}}$ value above the specimen measuring capacity.

For each individual test, the stress intensity rate at fracture is obtained by dividing the $K_{\mathrm{Jc}}$ value by the corresponding time to fracture $t_{\mathrm{f}}$.

\subsection{Master Curve analysis}

Each individual $K_{\mathrm{Jc}}$, calculated according to eqs. 6-10, is size-adjusted with respect to the thickness of a 25 mm-thick C(T) specimen $\left(1 \mathrm{TCT}^{5}\right)$ :

$$
K_{J C(1 T C T)}=20+\left(K_{K C(P C C)}-20\right)\left(\frac{B_{P C C}}{B_{1 T C T}}\right)^{1 / 4}
$$

where $B_{\text {PCC }}$ and $B_{1 \mathrm{TCT}}=25 \mathrm{~mm}$ are, respectively, the gross thicknesses (neglecting any sidegrooves) of the test specimen and the reference 1TCT specimen.

As mentioned above, any $K_{\mathrm{Jc}}$ value which exceeds the specimen capacity given by eq. 11 is censored and replaced with $K_{\mathrm{Jc}(\mathrm{limit})}$ in subsequent analyses.

A provisional dynamic reference temperature value, $T_{0 \mathrm{Q}}$, is calculated by iteratively solving the following equality [12,13]:

$$
\sum_{i=1}^{N} \delta_{i} \frac{\exp \left[0.019\left(T_{i}-T_{0 Q}\right)\right]}{11.0+76.7 \cdot \exp \left[0.019\left(T_{i}-T_{0 Q}\right)\right]}-\frac{\left(K_{J C(i)}-20\right)^{4} \cdot \exp \left[0.019\left(T_{i}-T_{0 Q}\right)\right]}{\left\{11.0+76.7 \cdot \exp \left[0.019\left(T_{i}-T_{0 Q}\right)\right]\right\}^{5}}=0
$$

where: $N$ = number of specimens tested;

$T_{\mathrm{i}}=$ test temperature;

$K_{\mathrm{Jc}(\mathrm{i})}=$ side-adjusted test result or censored value;

$\delta_{1}=1$ if the datum is valid or 0 if it's a censored value.

The provisional value $T_{0 \mathrm{Q}}$ is validated as the dynamic reference temperature of the material at the specific loading rate if:

$$
\sum_{i=1}^{3} r_{i} n_{i} \geq 1
$$

where $r_{\mathrm{i}}$ is the number of valid tests within the $\mathrm{i}$-th temperature range $\left(T-T_{0}\right)$, and $n_{\mathrm{i}}$ is the specimen weighting factor for the same temperature range as shown in Table 5.

${ }^{5} 1 \mathrm{TCT}=1$ in.-thick C(T) specimen. The thickness is rounded from $1 \mathrm{in} .=25.4 \mathrm{~mm}$ to $25 \mathrm{~mm}$. 
Table 5 - Weighting factors for Master Curve analysis.

\begin{tabular}{|cc|}
\hline $\begin{array}{c}\left(\boldsymbol{T}-\boldsymbol{T}_{\mathbf{0}}\right) \text { range } \\
\left({ }^{\mathbf{C}} \mathbf{C}\right)\end{array}$ & $\begin{array}{c}\text { Weighting factor } \\
\boldsymbol{n}_{\mathbf{i}}\end{array}$ \\
\hline 50 to -14 & $1 / 6$ \\
\hline-15 to -35 & $1 / 7$ \\
\hline-36 to -50 & $1 / 8$ \\
\hline
\end{tabular}

For the tests performed, the test temperature $\left(0^{\circ} \mathrm{C}\right)$ lies within the first range in Table 5 , so each one of the 23 valid tests contributes by 1/6. The relationship expressed by eq. 14 is therefore satisfied, and $T_{0 \mathrm{Q}}$ is validated as $T_{0, \mathrm{~d}}$.

The toughness/temperature transition curve (Master Curve) is given by:

$$
K_{J c(\text { med })}=30+70 \cdot \exp \left[0.019\left(T-T_{0}\right)\right]
$$

where $K_{\mathrm{Jc}(\mathrm{med})}$ is the median $K_{\mathrm{Jc}}$ toughness for $1 \mathrm{TCT}$ specimens. Upper and lower tolerance bounds (typically corresponding to $5 \%$ and $95 \%$ cumulative fracture probability) can be calculated by means of:

$$
K_{J(0 . x x)}=20+\left[\ln \left(\frac{1}{1-0 . x x}\right)\right]^{1 / 4}\left\{11+77 \cdot \exp \left[0.019\left(T-T_{0}\right)\right]\right\}
$$

where $0 . x x=0.05$ and 0.95 for the $5 \%$ and $95 \%$ tolerance bounds, respectively. 


\section{Results}

Out of 25 PCC specimens of 22NiMoCr37 shipped to NIST, 24 analyzable data sets were obtained. During the test on specimen B14, the data acquisition system did not trigger and the instrumented data were lost.

Only two of the 24 tested specimens (D3) provided $K_{\mathrm{Jc}}$ values which exceeded $K_{\mathrm{Jc}(\mathrm{limit})}$ given by eq. 11 and were therefore replaced with the limit values in the analyses. The summation in eq. 14 equals 3.677, based on 22 valid results. Table 6 reports individual values of $K_{\mathrm{Jc}(\mathrm{PCC}) \text {, }}$

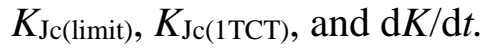

Table 6 - Individual test results. NOTE: invalid tests marked in red italic font.

\begin{tabular}{|c|c|c|c|c|}
\hline $\begin{array}{c}\text { Specimen } \\
\text { ID }\end{array}$ & $\begin{array}{c}K_{\text {Jc(PCC) }} \\
(\mathrm{MPa} \sqrt{\mathrm{m}})\end{array}$ & $\begin{array}{c}K_{\text {Jc(limit) }} \\
(\mathrm{MPa} \sqrt{\mathrm{m}})\end{array}$ & $\begin{array}{c}K_{\text {Jc(1TCT) }} \\
(\mathrm{MPa} \sqrt{\mathrm{m}})\end{array}$ & $\begin{array}{c}\mathrm{d} K / \mathrm{d} t \\
\left(10^{5} \mathrm{MPa} \sqrt{\mathrm{m}} / \mathrm{s}\right)\end{array}$ \\
\hline L2 & 85.3 & 172.6 & 71.9 & 3.09 \\
\hline E1 & 94.2 & 170.2 & 78.9 & 3.36 \\
\hline G7 & 107.2 & 172.2 & 89.3 & 3.25 \\
\hline D7 & 110.9 & 172.0 & 92.3 & 3.40 \\
\hline M12 & 112.2 & 170.7 & 93.3 & 3.35 \\
\hline M10 & 117.3 & 171.8 & 97.3 & 3.26 \\
\hline 4A & 118.7 & 172.0 & 98.5 & 3.25 \\
\hline M1 & 118.8 & 171.5 & 98.5 & 3.41 \\
\hline E10 & 119.1 & 171.9 & 98.8 & 3.46 \\
\hline K3 & 125.1 & 171.4 & 103.6 & 3.43 \\
\hline G3 & 131.7 & 170.0 & 108.7 & 3.43 \\
\hline L10 & 137.2 & 169.8 & 113.2 & 3.42 \\
\hline N14 & 137.9 & 170.1 & 113.7 & 3.41 \\
\hline L14 & 140.3 & 172.5 & 115.7 & 3.32 \\
\hline N6 & 144.4 & 170.0 & 118.9 & 3.37 \\
\hline 12A & 147.3 & 170.9 & 121.1 & 3.17 \\
\hline K7 & 147.6 & 170.9 & 121.6 & 3.35 \\
\hline M4 & 150.6 & 171.3 & 123.9 & 3.16 \\
\hline M2 & 150.9 & 172.0 & 124.1 & 3.25 \\
\hline D11 & 160.5 & 170.7 & 131.5 & 3.24 \\
\hline H9 & 166.5 & 171.3 & 136.6 & 3.15 \\
\hline E13 & 172.0 & 172.0 & 140.2 & 3.10 \\
\hline B2 & 175.7 & 169.4 & 138.1 & 3.06 \\
\hline D3 & 203.0 & 169.6 & 138.4 & 2.91 \\
\hline
\end{tabular}

The average stress intensity rate for the 24 tests analyzed was $3.3 \times 10^{5} \mathrm{MPa} \sqrt{\mathrm{m}} \pm 4.4 \%$.

The reference temperature, calculated by iteratively solving the equality in eq. 13 and validated by the condition expressed in eq. 14, is:

$$
T_{0}=-7.5^{\circ} \mathrm{C} \quad \text {. }
$$

The uncertainty of the calculated reference temperature is given by:

$$
\sigma=\sqrt{\frac{\beta^{2}}{r}+\sigma_{\exp }^{2}}
$$


where: $\quad \beta=$ sample size uncertainty factor;

$r=$ number of valid $K_{\mathrm{Jc}}$ results;

$\sigma_{\text {exp }}=$ contribution of experimental uncertainties (if standard calibration practices are followed, $\sigma_{\exp }=4^{\circ} \mathrm{C}$ ).

The value of the sample size uncertainty factor depends on the median toughness of the data set, which is expressed as [14]:

$$
K_{J C(\text { med })}^{e q}=\frac{1}{r} \sum_{i=1}^{r} 30+70 \cdot \exp \left[0.019\left(\left(T_{i}-T_{0}\right)\right]\right.
$$

For the data set under consideration, eq. 18 yields $K_{J c(\text { med })}^{e q}=110.7 \mathrm{MPa} \vee \mathrm{m}$, and therefore [15] $\beta=18{ }^{\circ} \mathrm{C}$. Substituting in eq. 17 , the uncertainty of the calculated reference temperature is therefore $\sigma=5.6{ }^{\circ} \mathrm{C}$.

The size-adjusted experimental data are shown in Figure 3 with the corresponding dynamic Master Curve (corresponding to $50 \%$ fracture probability), as well as the $5 \%$ and $95 \%$ tolerance bounds.

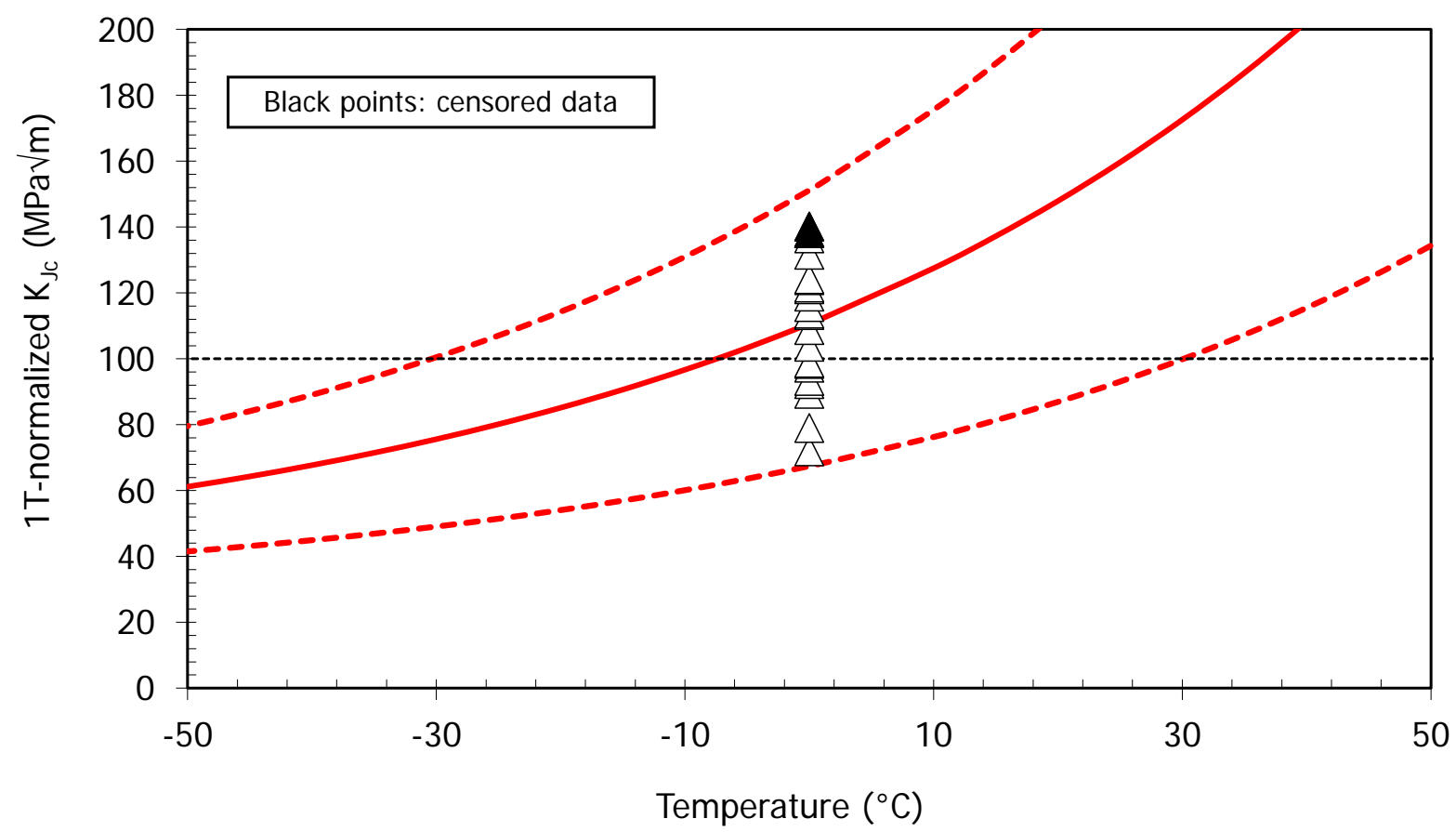

Figure 3 - Experimental data and dynamic Master Curves corresponding to $50 \%$ (solid curve), $95 \%$ (upper dashed curve), and $5 \%$ (lower dashed curve) fracture probabilities. 


\section{Discussion}

The value obtained at NIST for the dynamic reference temperature of 22NiMoCr37 by testing PCC specimens at an average loading rate of $3.28 \times 10^{5} \mathrm{MPa} \sqrt{\mathrm{m}} / \mathrm{s}, T_{0, \mathrm{~d}}=-7.5{ }^{\circ} \mathrm{C} \pm 5.6{ }^{\circ} \mathrm{C}$, is in excellent agreement with the value reported in [7,8] for PCC specimens (SE(B) $10 \times 10$ ) tested at $-20{ }^{\circ} \mathrm{C}$ at $2 \times 10^{5} \mathrm{MPa} \sqrt{\mathrm{m}} / \mathrm{s}\left(T_{0, \mathrm{~d}}=-7^{\circ} \mathrm{C}\right)$.

With respect to the quasi-static value of the reference temperature reported in [8], $T_{0}=-68{ }^{\circ} \mathrm{C}$, the increase in $T_{0}$ caused by the increase in loading rate is $62{ }^{\circ} \mathrm{C}$.

It has been contended [8] that dynamic fracture toughness could be limited by crack arrest effects, and therefore a lower-bound dynamic Master Curve (such as the $5 \%$ tolerance bound) should be limited by the ASME $K_{\mathrm{IR}}$ reference curve [6]. In reactor safety assessment, the $K_{\mathrm{IR}}$ curve is deemed to represent a lower bound for fracture toughness properties, particularly for accidental situations when high loading/strain rates are encountered. On this topic, the German government recently funded a collaborative research project between IWM and MPA to investigate the correlation between dynamic crack initiation and crack arrest: it was found that the $K_{\mathrm{IR}}$ curve effectively bounds dynamic fracture toughness properties measured from PCC specimens tested at impact loading rates [7]. Our results confirm the outcome of the German project, as shown in Figure 4: all experimental data, and the relevant 5 \% Master Curve, fall above the $K_{\mathrm{IR}}$ curve, which is given by:

$$
K_{I R}=26.78+1.223 \cdot \exp \left[0.0145\left(T-R T_{N D T}+160\right)\right]
$$

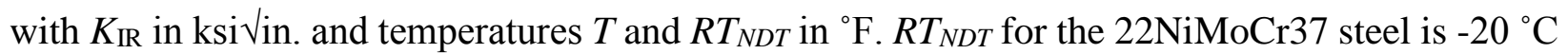
or $-4{ }^{\circ} \mathrm{F}$, according to Table 2 [8].

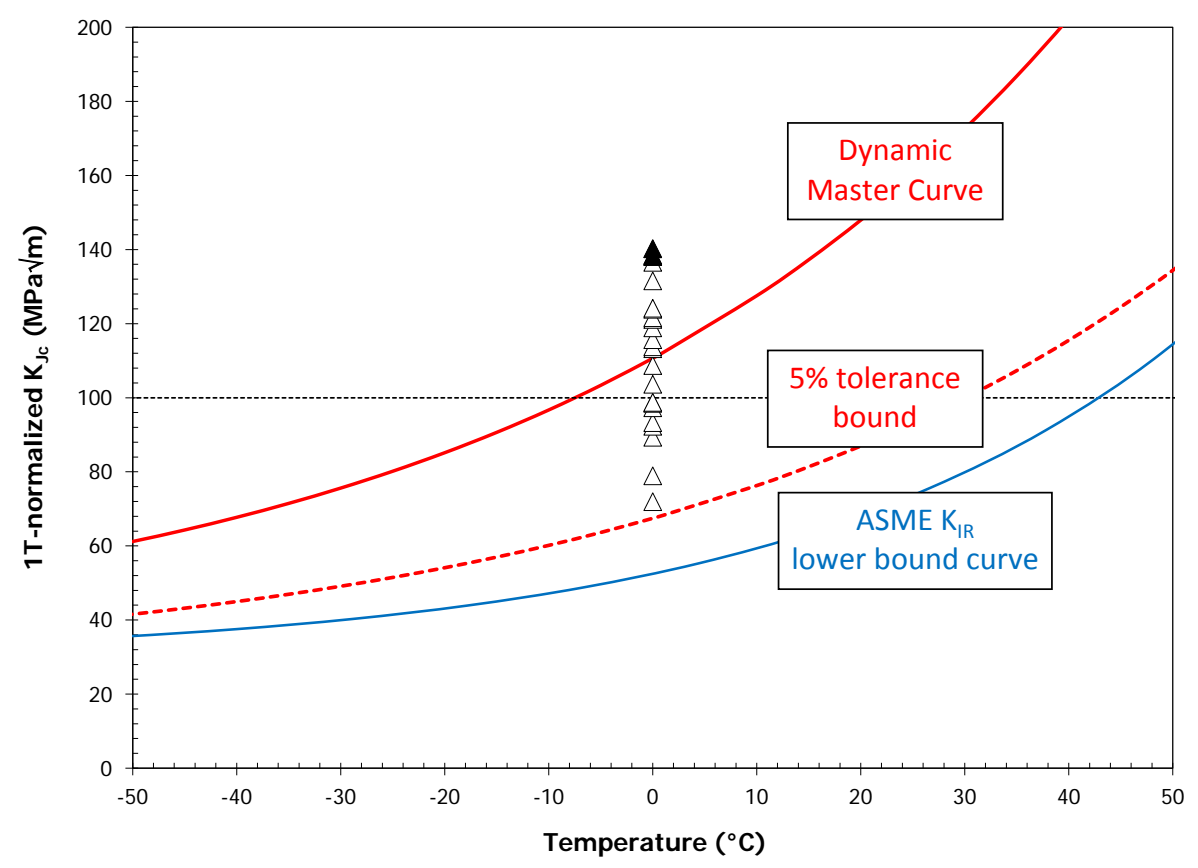

Figure 4 - Comparison between dynamic Master Curves and ASME KIR lower-bound curve. 
Other researchers have claimed that high loading rate data might not be represented satisfactorily by the Master Curve equation, eq. 15, which is typically used for quasi-static test data. In particular, Schindler and Kalkhof [16] claimed that the dynamic Master Curve is steeper, and proposed the following expression for the median Master Curve equation:

$$
K_{J c(\text { med })}=30+C \cdot \exp \left[p\left(T-T_{0}\right)\right],
$$

where the rate-dependent form factor $p$ equals 0.019 for quasi-static loading rates, but can increase up to 0.04 for impact loading rates on the order of $10^{5} \mathrm{MPa} \sqrt{\mathrm{m}}$. This would happen as a result of adiabatic heating at the crack tip caused by elevated loading rates, which tends to counteract the effect of dynamic embrittlement. Böhme et al. [8] used $p=0.03$ for their dynamic Master Curve evaluations. The results obtained by comparing eq. 15, corresponding to $p=0.019$, and eq. 20 with $C=70 \mathrm{MPa} \sqrt{\mathrm{m}}$ and $p=0.03$, are depicted in Figure 5 together with our experimental data after size adjustment. The reference temperature changes only by $2.2{ }^{\circ} \mathrm{C}\left(T_{0, p=0.03}=-5.3{ }^{\circ} \mathrm{C}\right)$.

With only one experimental data set, it's hard to confirm or refute Schindler's claim. We note that all the experimental data points are bounded by both the "conventional" $5 \%$ Master Curve and the alternative $5 \%$ confidence bound with $p=0.03$.

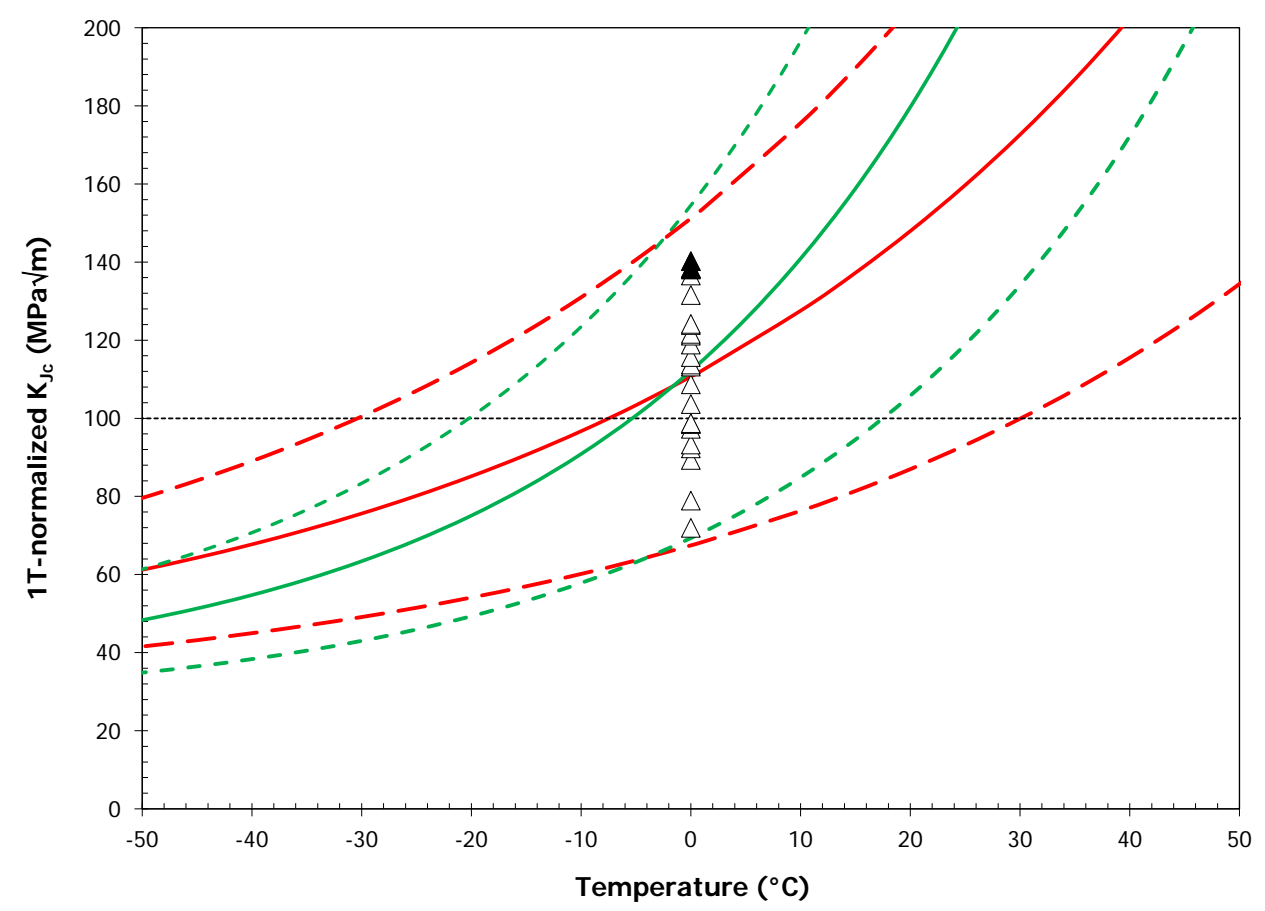

Figure 5 - Comparison between experimental data and Master Curves corresponding to eq. 15 (red curves) and to eq. 20 (green curves), that is $p=0.0019$ and $p=0.03$ respectively. 


\section{Conclusions}

The dynamic fracture toughness of a German pressure vessel steel, denominated 22MoNiCr37, was characterized in the ductile-to-brittle transition region by testing 25 precracked and side-grooved Charpy-type (PCC) specimens by means of an instrumented impact machine. Tests were performed at $0{ }^{\circ} \mathrm{C}$ with an impact velocity of $1.21 \mathrm{~m} / \mathrm{s}$, corresponding to a stress intensity factor rate (loading rate) on the order of $3 \times 10^{5} \mathrm{MPa} \sqrt{\mathrm{m}} / \mathrm{s}$. The fracture toughness values corresponding to unstable fracture, $K_{\mathrm{Jc}}$, were statistically evaluated in accordance with the Master Curve methodology (ASTM E1921-14a).

The value obtained for the dynamic reference temperature, corresponding to a median dynamic fracture toughness of $100 \mathrm{MPa} \sqrt{\mathrm{m}}$ for $1 \mathrm{TCT}$ specimens, was $T_{0, \mathrm{~d}}=-7.5{ }^{\circ} \mathrm{C}$, with a standard deviation of $5.6{ }^{\circ} \mathrm{C}$. Our results, which represent the NIST contribution to a cooperative project with IWM Freiburg and MPA Stuttgart (Germany), are in excellent agreement with results previously published by IWM.

As far as the author was able to ascertain, these are the first dynamic fracture toughness tests ever performed at NIST Boulder and the results look extremely promising in view of a future application of this methodology to other materials of interest to NIST, such as pipeline steels, ultrahigh-energy steels, welded joints, etc.

\section{Acknowledgments}

The author gratefully acknowledges Ray Santoyo's collaboration during the execution of the impact tests. 


\section{References}

[1] ASTM E1921-14a, "Standard Test Method for Determination of Reference Temperature, $T_{o}$, for Ferritic Steels in the Transition Range,” ASTM Book of Standards, Vol. 03.01, ASTM International, West Conshohocken, PA.

[2] K. Wallin, T., Saario, and K. Törrönen, "Statistical Model for Carbide Induced Brittle Fracture in Steel,” Metal Science, Vol. 18, January 1984, pp. 13-16.

[3] K. Wallin, "Statistical Modelling of Fracture in the Ductile to Brittle Transition Region," in: Defect Assessment in Components - Fundamentals and Applications, ESIS/EGF9, J.G. Blauel and K.-H. Schwalbe, Eds., 1991, pp. 415-445.

[4] T. L. Anderson, D., Steinstra, and R. H. Dodds, "A Theoretical Framework for Addressing Fracture in the Ductile-Brittle Transition Region," in: Fracture Mechanics, $24^{\text {th }}$ Volume, ASTM STP 1207, ASTM, 1994, pp. 185-214.

[5] International Atomic Energy Agency, "Master Curve Approach to Monitor Fracture Toughness of Reactor Pressure Vessels in Nuclear Power Plants,” IAEA-TECDOC-1631, Vienna (Austria), 2009.

[6] American Society of Mechanical Engineers, Appendix G: "Protection against Nonductile Failure,” ASME Section III, Div. 1.

[7] W. Böhme, U. Mayer, T. Reichert, S. Offermanns, A. Allmendinger, M. Hug, J. Schüler, and D. Siegele, "Überprüfung und Weiterentwicklung von Bewertungsmethoden für dynamische Rissinitierung und Rissarrest”, BMWi-Vorhaben Nr. 150 1368. Fraunhofer IWM report $665 / 2012$.

[8] W. Böhme, T. Reichert, and U. Mayer, “Assessment of Dynamic Fracture Toughness Values $K_{J c}$ And Reference Temperatures $T_{0, X}$ Determined for a German RPV Steel at Elevated Loading Rates according to ASTM E1921," Transactions, SMiRT-22, San Francisco, California, USA, August 18-23, 2013.

[9] ASTM E2298-13a, "Standard Test Method for Instrumented Impact Testing of Metallic Materials,” ASTM Book of Standards, Vol. 03.01, ASTM International, West Conshohocken, PA.

[10] D. R. Ireland, "Procedures and Problems Associated with Reliable Control of the Instrumented Impact Test,” in: Instrumented Impact Testing, ASTM STP 563, T. S. DeSisto, Ed., American Society for Testing and Materials, Philadelphia PA, 1974, pp. 3-29.

[11] W. L. Server, "General Yielding of Charpy V-Notch and Precracked Charpy Specimens," Journal of Engineering Materials and Technology, Vol. 100, Apr 1978, pp. 183-187.

[12] K. Wallin, "Validity of Small Specimen Fracture Toughness Estimates Neglecting Constraint Corrections," in: Constraint Effects in Fracture: Theory and Applications, ASTM STP 1244, M. Kirk and A. Bakker, eds., ASTM, 1994, pp. 519-537.

[13] J. G. Merkle, K.Wallin, and D. E. McCabe, "Technical Basis for an ASTM Standard on Determining the Reference Temperature, $T_{o}$, for Ferritic Steels in the Transition Range," NUREG/CR-5504 (ORNL/TM-13631), November 1998.

[14] E. Lucon, M. Scibetta, and E. van Walle, “Assessment of the Master Curve approach on three reactor pressure vessel steels,” International Journal of Fracture 119, pp. 161-178, 2003.

[15] K. Wallin, "Master Curve Analysis of Ductile to Brittle Transition Region Fracture Toughness Round Robin Data (The Euro Fracture Toughness Curve)," VTT Technical Document 367.58P, Espoo, Finland, 1998. 
[16] H.-J. Schindler and D. Kalkhof, "Lower bounds and saturation effects of dynamic fracture toughness in the brittle-to ductile transition regime of ferritic steels," Transactions, SMiRT22, San Francisco, California, USA, August 18-23, 2013. 